\title{
POTENTIAL BENEFITS OF A CONCURRENT VERBAL TASK WHEN FEELING FATIGUED DUE TO MONOTONOUS DRIVING CONDITIONS
}

\author{
Mark Chan \& Paul Atchley \\ University of Kansas \\ Lawrence, Kansas, USA \\ Email: mchan5@ku.edu
}

\begin{abstract}
Summary: Work by Atchley and Chan (2011) reported that engaging in a concurrent verbal task might serve to alleviate performance decrements in drivers when vigilance was low. Building on previous findings, the current study investigated the potential benefits of a concurrent verbal task when drivers were likely to be fatigued due to the extended duration and monotony of a driving task. Driver performance was studied under distracted and non-distracted conditions. Results indicated that strategically engaging in a concurrent verbal task led to improved driving performance when fatigue was at its highest.
\end{abstract}

\section{INTRODUCTION}

Driving under monotonous conditions for extended periods of time will likely to lead to decrements in driving performance (Thiffault \& Bergeron, 2003). A 2008 National Highway Traffic Safety Administration (NHTSA) survey reported that approximately 62,000 nonperformance related crashes were due to driver fatigue, or drivers physically falling asleep while driving (NHTSA, 2008). Most drivers are aware of the risks involved when driving tired, and many understand that the best option is to take a break. Yet to minimize the inconvenience of stopping and having to make up for lost time, drivers often employ a variety of self-initiated countermeasures in an attempt to minimize the effects of fatigue (Nordbakke \& Sagberg, 2007). The efficacy of these self-initiated countermeasures e.g. turning up the air-conditioning is often short-lived (Reyner \& Horne, 1998).

In situations where drivers are clearly exhibiting fatigue, stopping to take a break is the best option (Nguyen, Jauregui, \& Dinges, 1998). Yet not all drivers have the luxury of doing so, for example military convoy driving under hostile conditions. One countermeasure that military truck drivers perceived as particularly effective is to engage in a cell phone conversation (OronGilad \& Shinar, 2000). Furthermore, Drory (1985) reported that a simple task of periodically reporting odometer readings improved driver performance when driving continuously for an extended duration. Recent work by Gershon, Ronen, Oron-Gilad, and Shinar (2009) reported that an interactive cognitive task led to improvements in driving performance when employed as a countermeasure against driver fatigue.

The appeal of using an interactive cognitive task, engaging in cell phone conversation or any other concurrent task as a fatigue countermeasure is tempered by the risk of distraction. The 2008 NHTSA survey also reported that almost half a million performance related crashes occur annually. These crashes were attributed to drivers exhibiting "inadequate surveillance" or "inattention”. Redelmeier and Tibshirani (1997) found a fourfold increase in crash risk when drivers were distracted by cell phone conversations. Further investigations also found that 
distracted drivers generally exhibit poorer driving performance, e.g. poor lateral control, greater speed variability, decreased visual attention (Rakauskas, Gugerty, \& Ward, 2004; Strayer \& Drews, 2007). However, analysis of naturalistic driving data in commerical vehicles found no increased risk of crashes when speaking on the cellphone. More intriguing was the finding that cell phone conversations decreased the risk of accidents. (Hickman, Hanowski, \& Bocanegra, 2010; Olson, Hanowski, Hickman, \& Bocanegra, 2009)

In a comparatively shorter drive (30 min vs. 90 min) Atchley and Chan (2011) reported improvements in driving performance when a concurrent verbal task was strategically introduced at the end of the drive. The current study focused primarily on the strategic application of a concurrent task as a countermeasure late in the drive. We viewed fatigue as a general state that arises due to prolonged driving under monotonous conditions, and not sleep deprivation. Thus, the effects of fatigue while driving under monotonous conditions may include decrements in vigilance and energetic arousal. It is also suggested that fatigue leads to a decrease in effortful task engagement (Brown, 1994; Hockey, 1997). Given that fatigue and distraction impact driving performance negatively, the primary focus of this study was to investigate the potential arousing or disruptive effects on driving performance due to a concurrent verbal task especially when drivers were fatigued. It was hypothesized that the introduction of a concurrent verbal task may improve driving performance by reducing monotony and fatigue. Along the lines of optimal performance as suggested by Yerkes and Dodson (1908), the arousing effect was hypothesized to be strongest at the last driving block.

\section{METHOD}

\section{Participants}

Participants were recruited by flyers posted on campus. 9 males and 3 females $(M=20.8$ years, $\mathrm{SD}=1.8$ ), received an honorarium of $\$ 50$ upon completing the study. All participants had an average of 2.9 years of driving experience $(S D=5.5)$. Participants without a current driver's license were not included in the study. Participants had to be free from any prior brain injury, known neurological disease, and were not on any long term medication. Participants reported English as their native language, and had normal or corrected to normal vision. To avoid confounds, the following protocol was used for all sessions: 1.Testing occurred between 9am to noon and 2pm to 5pm to avoid circadian lulls. 2. At least seven hours of sleep prior to a session. 3. Abstinence from alcohol for 24 hours and caffeine 12 hours prior to a test session. 4 . Sessions were spaced at least 24 hours apart. Participants drove in all three task conditions, No Verbal (NV), Late Verbal (LV), where the verbal task was introduced only in the last block, and Continuous Verbal (CV) where participants engaged in the verbal task for approximately 4 minutes in each block. Order was counterbalanced across participants.

\section{Driving \& Verbal Task}

Scenario. All participants drove in the same simulated environment designed on the STISIM Drive simulator software (Systems Technology Inc. Hawthorne, CA). The roadway was a fourlane rural highway separated by a median. The width of each lane width was $12 \mathrm{ft}$ across. The roadway was generally flat and monotonous, with occasional curves and sporadic traffic in both 
directions to ensure a degree of realism. Visibility was set at $1500 \mathrm{ft}$ under clear conditions. The environment was designed to mimic conditions on rural highways. Twenty-seven unique billboards chosen from a variety of gas stations, motels, and fast food chains commonly seen in North America were placed on the right shoulder of the roadway. Each driving block had three billboards. There were a total of nine blocks of 12 miles, resulting in approximately 108 miles of data. Each block represented about 10 minutes of driving for a total duration of about 90 minutes. There was a one mile start up distance to allow drivers to get up to speed. An additional half mile wind-down distance was included at the end to reduce 'end of task' performance spurts. The total driving distance was approximately 109.5 miles. Drivers were instructed to remain in the left lane for the duration of the drive. Traffic always travelled slower than the driver to ensure successful passing.

Car following. To add to the monotony of the scenario, drivers had to follow a lead vehicle at a safe distance for the duration of the drive at an average speed of $75 \mathrm{mph}$. The speed profile of the lead vehicle was defined pseudo-randomly by using a sum of three sine waves. To maintain an acceptable following distance, drivers had to respond appropriately to the fluctuating speed of the lead vehicle. If the driver's following distance was greater than $200 \mathrm{ft}$ an auditory warning would inform the driver to catch up with the lead vehicle.

Verbal task. Conversations require listeners to encode and retrieve pertinent information about the topic. Thus the ability to retell a narrative becomes an important component of the conversation (Becic et al., 2010). 20 narratives were selected from Becic et al., (2010) and an additional 16 were generated by our laboratory to ensure sufficient narratives for the entire drive. The narratives were pre-recorded by a female native speaker of English and presented via handsfree kit to drivers in both concurrent verbal task conditions. Each narrative lasted approximately $20 \mathrm{sec}$ and was randomly presented, without replacement, by E-prime (Version 2.0). At the end of each narrative, drivers were given 30 sec to retell the narrative. Accuracy and clarity of retelling was emphasized. Drivers listened to and retold four narratives in each block. The duration of the verbal task within each block was approximately $4 \mathrm{~min}$. The onset of the verbal task was controlled by the experimenter. All verbal responses were recorded for future analysis.

\section{Performance Measures}

Standard deviation of lane position (SDLP). Lateral stability was assessed by the standard deviation of lane position (SDLP). With a decrease in vigilance, and the onset of fatigue, the magnitude of SDLP generally increases (Desmond \& Matthews, 1997). Lane and road shoulder intrusions also indicate poorer lane keeping. These were assessed by taking into account the number of times a driver straddles the lane divider and instances where the driver drove off the roadway. Liu and Wu (2009) suggested that an increase in the number of intrusions indicate decreased attention.

Car following. Given that the distance from a lead vehicle might indicate a margin of safety, Young, Regan and Lee (2009) suggest that shorter distances indicate poorer driving performance. However, Strayer, Drews and Johnston (2003) reported that drivers who were distracted by a cell phone conversation maintained greater separation from a lead vehicle, suggesting compensatory behavior. 


\section{RESULTS}

Before investigating the hypothesized effects, initial analysis using 3(Task) x 9(Time) repeated measures ANOVA were run on all measures to check for decrements with time on task. There was a significant effect of time on task for all performance measures (all $F s>8.90 ; p<.001$ ). Performance decreased over time. To investigate the effects of the concurrent verbal task when fatigue was at its highest, all analysis focused on the last two blocks of the drive (or the last 20 minutes of the 90 minute drive) using a 3(Task) x 2(Time) repeated measures ANOVA.

\section{Standard Deviation of Lane Position (SDLP)}

For this analysis all instances where the vehicle was out of the left lane were removed before computing results. There was a significant main effect of Time $F(1,11)=7.51, p<.05, \eta^{2}=$ .41 , and a significant Time $\mathrm{x}$ Task interaction $F(2,22)=25.83, p<.001, \eta_{p}^{2}=.70$ (see Figure 1a). Paired sample t-tests found a significant decrease in SDLP for the Late Verbal task $t(11)=$ 6.42, $p<.001$, between the eighth $(\mathrm{M}=1.61 \mathrm{ft}, \mathrm{SD}=.25)$ and ninth block $(\mathrm{M}=1.34 \mathrm{ft}$, $\mathrm{SD}=$ .26). There were no significant changes in SDLP for the No Verbal and Continuous Verbal Task groups (all $p$ 's $>$.27) between the two time blocks (see Figure 1a). Planned comparisons at the ninth time block found a significant difference in SDLP between No Verbal $(\mathrm{M}=1.50 \mathrm{ft}, \mathrm{SD}=$ $.27)$ and Late Verbal $(\mathrm{M}=1.34 \mathrm{ft}, \mathrm{SD}=.26)$ Tasks, $t(11)=2.87, p<.05$. Participants who engaged in the verbal task only at the end exhibited better control of the vehicle. Differences between No Verbal $(\mathrm{M}=1.50 \mathrm{ft}, \mathrm{SD}=.27)$ and Continuous Verbal $(\mathrm{M}=1.37 \mathrm{ft}, \mathrm{SD}=.23)$ Tasks were marginally significant, $t(11)=2.09, p=.06$. There was no significant difference in SDLP between Continuous and Late Verbal Tasks, $p=.60$.

(a)

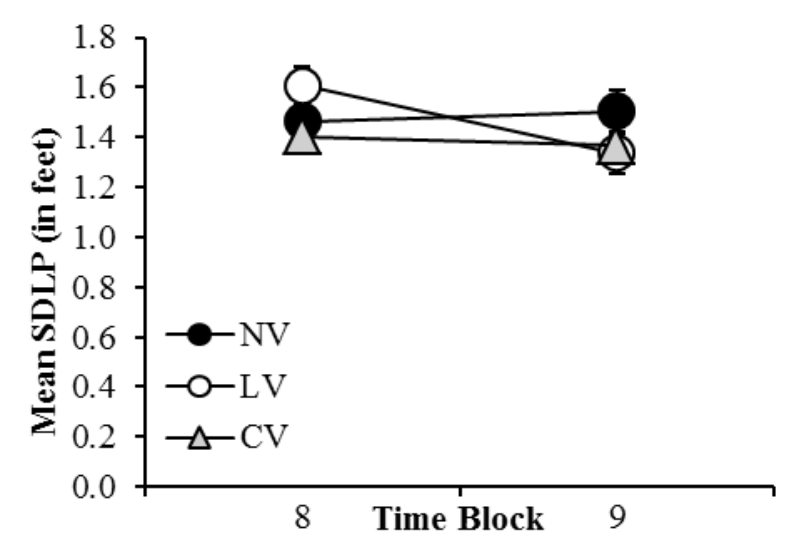

(b)

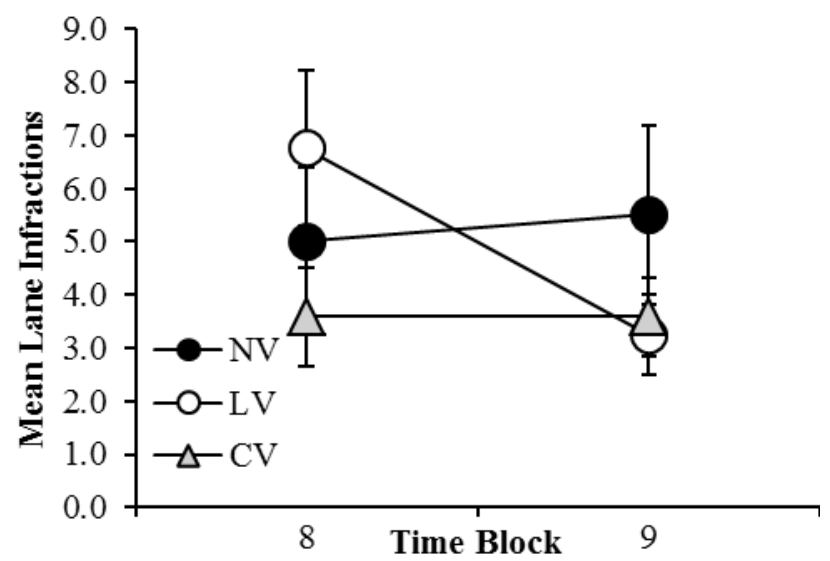

Figure 1. (a) Decrease in SDLP for Late Verbal Task with the introduction of a verbal task at Block 9; (b) Decrease in infractions for Late Verbal Task with the introduction of the verbal task at Block 9

\section{Lane Infractions}

(all error bars are S.E. mean)

There was a significant Time $\mathrm{x}$ Task interaction $F(2,22)=4.12, p<.05, \eta_{p}^{2}=.27$ (see Figure 1b). There were no effects for Task or Time (all $p$ 's $>$.17). Paired sample t-tests found a significant decrease in infractions for the Late Verbal task $t(11)=2.79, p<.05$, between the 
eighth $(\mathrm{M}=6.75, \mathrm{SD}=4.63)$ and ninth $(\mathrm{M}=3.25, \mathrm{SD}=2.38)$ block. There were no significant changes in lane infractions for the No Verbal and Continuous Verbal tasks (all $p$ 's $>$.68) between the two time blocks. Planned comparisons did not reveal significant differences between Tasks at the ninth block (all $p$ 's $>.14$ ).

\section{Car Following}

There was main effect of Task $F(2,22)=6.68, p<.01, \eta^{2}=.38$, and a marginally significant effect of Time $F(1,11)=4.08, p=.07, \eta_{p}^{2}=.27$. Driving and engaging in Continuous Verbal Task led to shorter following distances (see Table 3). There was no significant Time $\mathrm{x}$ Task interaction $(p=.98)$. Planned comparisons indicated that the Late Verbal Task exhibited a greater following distance compared to the Continuous Verbal Task $t(11)=2.43, p<.05$ (see Table 1). All other comparisons did not achieve statistical significance (all $p$ ’s $>.14$ ).

Table 1. Means (and standard deviations) of average following distance (in feet) for Blocks 8 and 9

\begin{tabular}{lcc}
\hline & \multicolumn{2}{c}{ Time Block } \\
\cline { 2 - 3 } Task & 8 & 9 \\
\hline No Verbal Task & $124.85(19.10)$ & $117.94(19.21)$ \\
Late Verbal Task & $129.39(24.79)$ & $123.39(17.59)$ \\
Continuous Verbal Task & $115.65(28.94)$ & $109.19(26.75)$ \\
\hline
\end{tabular}

\section{DISCUSSION}

The results from the current study support the use of a strategically employed concurrent task as a potential countermeasure against performance decrements. In general, performance decreased over time consistent with increasing fatigue (Desmond \& Matthews, 1997). The introduction of a concurrent task at the last block led to improved lateral stability, corroborating previous research by Atchley and Chan (2011). In addition to improved lateral stability, drivers also exhibited a decrease in lane infractions. The current results extend previous findings by showing similar effects when participants were fatigued. Therefore, it is possible that the onset of a concurrent verbal task late in the drive functions as a cognitive load that increases arousal and overall task engagement especially when drivers are fatigued. However, these results should be viewed with caution. The improvements were only observed when performance was compared to conditions where no concurrent task was present i.e. No Verbal Task and Block Eight of the Late Verbal Task. There was no significant difference when performance was compared to the continuous concurrent task condition. It is clear that a late concurrent task does improve driving performance, but performance is only comparable to drivers in the continuous verbal task group. Contrary to Strayer et al., (2003) drivers who engaged in the Continuous Verbal Task maintained a shorter following distance rather than exhibit compensatory behaviors due to the distraction of the concurrent verbal task. These results support the notion that distraction from a concurrent task leads to a poorer margin of safety (Alm \& Nilsson, 1995; Young, et al., 2009). Unlike external distractors such as cell phone conversations, fatigue is considered to be an internal source of distraction that can also influence attention (Williamson, 2009). Thus it is possible that the combined effects of a continuous concurrent task and increasing fatigue led to greater decrease in safety margins. The significant difference in following distance at the last block between Late Verbal Task and Continuous Verbal Task suggests may therefore indicate 
increased alertness and engagement. The onset of a late concurrent task may decrease internal distraction induced by fatigue, which consequently leads drivers to exhibit compensatory following behaviors by increasing their margin of safety.

\section{CONCLUSIONS}

Admittedly, the limitation of this study was the decision to focus only on the final two periods of the drive. Nonetheless, driving performance improved with the strategic employment of a concurrent task. This may explain why commercial truck drivers are less likely to get into crashes when speaking on cell phones (Hickman, et al., 2010; Olson, et al., 2009). While performance did improve with the Late Verbal Task, it is important to note that performance levels are similar to the Continuous Verbal Task condition. Given that performance in the Continuous Verbal Task is influenced by a combination of fatigue and distraction, the effectiveness of a strategic concurrent task is in question. Future studies should investigate the possibility of maintaining performance by varying the degree of difficulty of the concurrent task.

\section{ACKNOWLEDGEMENTS}

This project was funded by a grant from the University of Kansas Transportation Institute.

\section{REFERENCES}

Alm, H., \& Nilsson, L. (1995). The effects of a mobile telephone task on driver behaviour in a car following situation. Accident Analysis and Prevention, 27, 707-715.

Atchley, P., \& Chan, M. (2011). Potential Benefits and Costs of Concurrent Task Engagement to Maintain Vigilance. Human Factors: The Journal of the Human Factors and Ergonomics Society, 53(1), 3-12.

Becic, E., Dell, G., Bock, K., Garnsey, S., Kubose, T., \& Kramer, A. (2010). Driving impairs talking. Psychonomic Bulletin \& Review, 17, 15-21.

Brown, I. D. (1994). Driver Fatigue. Human Factors, 36, 298-314.

Desmond, P. A., \& Matthews, G. (1997). Implications of task-induced fatigue effects for invehicle countermeasures to driver fatigue. Accident Analysis \& Prevention, 29, 515-523.

Drory, A. (1985). Effects of rest and secondary task on simulated truck-driving task performance. Human Factors, 27, 201-207.

Gershon, P., Ronen, A., Oron-Gilad, T., \& Shinar, D. (2009). The effects of an interactive cognitive task (ICT) in suppressing fatigue symptoms in driving. Transportation Research Part F, 12, 21-28.

Hickman, J., S., Hanowski, R. J., \& Bocanegra, J. (2010). Distraction in commercial trucks and buses: Assessing prevalence and risk in conjunction with crashes and near-crashes. (FMCSA-RRR-10-049). Washington, DC: U.S. Department of Transportation.

Hockey, G. R. J. (1997). Compensatory control in the regulation of human performance under stress and high workload: A cognitive-energetical framework. Biological Psychology, 45(13). 
Liu, Y. C., \& Wu, T. J. (2009). Fatigued driver's driving behavior and cognitive task performance: Effects of road environments and road environment changes. Safety Science, 47, 1083-1089.

National Highway Traffic Safety Administration. (2008). National motor vehicle crash causation survey (DOT HS 811 059). Retrieved from http://www-nrd.nhtsa.dot.gov/Pubs/811059.PDF

Nguyen, L. T., Jauregui, B., \& Dinges, D. F. (1998). Changing behavior to present drowsy driving and promote traffice safety: Review of proven, promising, and unproven techniques. AAA Foundation for Traffic Safety. Washington, DC.

Nordbakke, S., \& Sagberg, F. (2007). Sleepy at the wheel: Knowledge, symptoms and behaviour among car drivers. Transportation Research Part F: Traffic Psychology and Behaviour, 10, $1-10$.

Olson, R., L., Hanowski, R. J., Hickman, J., S., \& Bocanegra, J. (2009). Driver distraction in commercial vehicle operations. (FMCSA-RRR-09-042). Washington, DC: U.S. Department of Transportation.

Oron-Gilad, T., \& Shinar, D. (2000). Driver fatigue among military truck drivers. Transportation Research Part F, 3, 195-209.

Rakauskas, M. E., Gugerty, L. J., \& Ward, N. J. (2004). Effects of naturalistic cell phone conversations on driving performance. Journal of Safety Research, 35, 453-464.

Redelmeier, D. A., \& Tibshirani, R. J. (1997). Association between cellular-telephone calls and motor vehicle collisions. The New England Journal of Medicine, 336, 453-458.

Reyner, L. A., \& Horne, J. A. (1998). Evaluation of 'in-car' countermeasures to sleepiness: Cold air and radio. Sleep, 21(1), 46-50.

Strayer, D. L., \& Drews, F. A. (2007). Cell phone induced driver distraction. Current Directions in Psychological Science, 16(3), 128-131.

Strayer, D. L., Drews, F. A., \& Johnston, W. A. (2003). Cell phone-induced failures of visual attention during simulated driving. Journal of Experimental Psychology: Applied, 9(1), 2332.

Thiffault, P., \& Bergeron, J. (2003). Fatigue and individual differences in monotonous simulated driving. Personality and Individual Differences, 34, 159-176.

Williamson, A. (2009). The relationship between driver fatigue and driver distraction. In M. A. Regan, J. D. Lee \& K. L. Young (Eds.), Driver distraction: Theory, effects, and mitigation (pp. 383-392). Boca Raton, FL: CRC Press.

Yerkes, R. M., \& Dodson, J. D. (1908). The relation of strength of stimulus to rapidity of habitformation. Journal of Comparative Neurology and Psychology, 18, 459-482.

Young, K. L., Regan, M. A., \& Lee, J. D. (2009). Measuring the effects of driver distraction: Direct driving performance methods and measures. In M. A. Regan, J. D. Lee \& K. L. Young (Eds.), Driver distraction: Theory, effects and mitigation (pp. 85-106). Boca Raton, FL: CRC Press. 